\title{
A Social History of Madness -or, Who's Buying This Round? Anticipating and Avoiding Gaps in Collection Development
}

\author{
Paul Metz and Béla Foltin, Jr.
}

Both the internal organization of collection development and the nature of science and scholarship lead to inevitable gaps in collection development. The discussion identifies both nondisciplinary and interdisciplinary areas especially vulnerable to such oversight and suggests remedies to prevent the undue perpetuation of gaps.

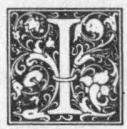

$t$ is generally conceded that even the best collection development programs will have gaps, so that works of potential value in a number of areas will simply not be acquired. The effort to discover and remedy such gaps consumes much of the time of most collection development staff.

Very often individual titles of value are missed simply because they fall into multiple subjects whose respective selectors are not communicating, and consequently play an unwitting game of Alphonse and Gaston. Roy Porter's A Social History of Madness, which furnishes our title, invites this sort of mutual deference among the three or more selectors to whom this title could be of interest.

An occasional missed title is an unfortunate inevitability, an event that will happen, even though the frequency with which valuable books are overlooked can be controlled. A gap-the recurring failure to acquire valuable materials in a given area-is more serious. The long-term failure to collect in a subject area is a serious problem, but one which can be avoided.

It is the purpose of this discussion to help collection development librarians avoid the perpetuation of gaps. We hope to do this by analyzing the structural and intellectual causes of collection development gaps, and by listing a number of areas whose literatures are especially vulnerable to being ignored or overlooked by selectors.

\section{CAUSES OF COLLECTION DEVELOPMENT GAPS \\ Organizational Causes}

It goes without saying that the days of the University Bibliographer responsible for selection in all areas are long gone. One may question whether it was ever possible for a single individual to collect in all areas, but clearly the growth and increased specialization of all disciplines make this a dead issue today.

The necessity to allocate collection development responsibilities to a number of individuals has led to a great diversity of organizational structures. The reporting

Paul Metz is Principal Bibliographer and Béla Foltin, Jr. is Assistant Director for Public Services and Collection Development at Virginia Tech, Blacksburg, Virginia 24061. 
lines, divisions of responsibility, and other structural features of these various approaches have been thoughtfully reviewed elsewhere, most recently by James Cogswell. ${ }^{1}$

The most important distinction for our purposes is that between approaches which make university department or program the key basis for the division of labor among selectors and those which match selection assignments to subject or discipline. A third approach-by language group and publication area of the worldis less frequently used. All of these philosophical approaches are compatible with any of the various structural models.

The assignment of selection responsibilities by academic department may be compared to the use of a man-to-man defense in football. Selectors attempt to "chase" their departments all around the field of knowledge. As in football, individuals with these assignments are easily deceived about the directions of those they are assigned to cover. Selectors may also risk colliding fairly frequently in their efforts to cross and recross the field.

The assignment of selection responsibilities by subject or discipline is analogous to a zone defense. Selectors cover an area, and in effect build collections for the use of whoever may enter that area. As in football, there are invariably gaps between the various zones of responsibility. The subject approach has a number of compensating strengths not shared by the departmental approach. One is that (as in football) individual selectors can help inexperienced or underfunded colleagues by subtly redefining the zones of responsibility. A second is that the disciplinary approach is more likely to secure for the collection at least a representative sampling of materials in areas that will be of future research interest but are not currently being pursued.

Collection development assignments in most university libraries represent a hybrid of these approaches. A selector will be assigned to sociology, for example, with the understanding that he or she is primarily responsible for the academic discipline bearing that name, but secondarily responsible to acquire materials, or to make sure that other selectors acquire materials, supporting any current research and instructional interests of the department which transcend the normal boundaries of sociology as a discipline. If a faculty sociologist conducts extensive research on coalition formation within the nineteenth-century British Parliament, the selector for sociology should at least make sure that the selectors in history and political science are aware of this interest and will buy supporting materials.

\section{"Because the very basis of allocation is by subject or department, whole areas of knowledge which fall out- side the scope of traditional disci- plines are ignored."'}

Either approach to assigning responsibilities, or any combination of the two, is likely to generate gaps for several reasons. First, because the very basis of allocation is by subject or department, whole areas of knowledge which fall outside the scope of traditional disciplines are ignored. There are many nondisciplinary areas in which practical, entertaining, or instructive materials are published. While most academic libraries accept a theoretical responsibility to serve a public library function to some degree, and all aspire to support various nondepartmental agencies on campus, these nondisciplinary areas are easily overlooked by schemes whose "first cut" is by definition disciplinary.

An additional problem with subject or disciplinary approaches is that of defining the fields so that emerging or interdisciplinary areas are covered. To clarify assignments and thereby minimize the interdisciplinary areas which will not be in scope for a selector, libraries often define responsibilities in part by call number area. The use of call numbers introduces yet a third dimension, one which often clarifies but sometimes confuses departmental and disciplinary definitions. That most books treating current affairs in various world areas bear Library of Congress call numbers that ostensibly correspond with 
historical materials is but the most obvious example of this problem.

\section{Intellectual Causes}

In general, gaps will flourish the most in and around academic disciplines with weakly defined paradigms. A discipline like geography, which draws broadly on the social and natural sciences, will present far greater difficulties to a selector than will mathematics, most of whose research draws in a highly focused way on previous work within the discipline. Of course, even the "tightness" of the mathematics literature does not guarantee that it will be easy for the selector in mathematics to anticipate the particular needs of statisticians, physicists, or other external users of materials in mathematics.

It is a trusim that academic disciplines are changing rapidly and that a disproportionate share of change takes place at the intersections of traditional disciplines. Charles Osburn has cogently summarized a number of recent changes in scholarship and research, such as the increased quantification of the social sciences, a trend in literary criticism towards close analysis of the text and away from historical analysis, and the growing dependence of scientific progress on technological developments. Osburn has shown how these changes create new challenges in collection development. $^{2}$

New developments in academic or scientific fields often entail the redefinition of those fields, as Thomas Kuhn has shown. ${ }^{3}$ In time, a new field emerges or the definition of an existing field expands to embrace the new technique or theoretical understanding. In the interim, however, the area is conspicuously interdisciplinary and is easily overlooked by disciplinebased selection programs. Current examples of books which challenge existing paradigms and therefore are marginal to scientific disciplines as presently defined are James Gleick's Chaos: Making a New Science, which challenges the mathematical and philosophical underpinnnings of strict scientific causality; and James Lovelock's The Ages of Gaia, which would dramatically shift the intellectual constructs of a number of life sciences. These books are more nearly supradisciplinary than interdisciplinary at this point, although their perspectives may in time be embraced by new or existing disciplines.

Interdisciplinary areas sometimes arise from the borrowing of research techniques. Recent developments in scanning electron microscopy and in magnetic resonance imaging have been applied in a number of areas, including medicine, but remain sufficiently arcane that their literatures draw heavily on their fields of origin.

Interdisciplinary areas also arise when the traditional bases of division among fields are disregarded or refuted by those who champion new areas of study. Area studies, black studies, and women's studies are inherently interdisciplinary because they reject the distinctions of philosophy and methods which have been historically defined the various academic disciplines, and instead define their areas in terms of subject matter. The same could be said of science studies, which draws on philosophy, sociology, history, and other disciplines to study the topical domain which defines it as a field.

While changes emanating from various intellectual disciplines may readily change disciplinary boundaries and create new interdisciplinary areas, larger intellectual forces present in the academy or in the general zeitgeist may redefine the boundary between what is considered to be disciplinary and what is not. For example, women's studies proponents and others have sought to redefine the literary canon to include hitherto neglected writers or even published diarists whose sex, race, or nationality have been underrepresented in traditional studies. When suc-

"The postmodern spirit also assumes
an integration of political, social, ar-
tistic, and literary life so fundamen-
tal as to challenge both disciplinary
boundaries and the very theoretical
and methodological approaches the
traditional disciplines have taken to
their subject matters." 
cessful, these efforts move their personages into the domain of legitimate literary studies and out of the realm of the popular (or unpopular, as the case may be). ${ }^{4}$

Even more fundamental changes in intellectual life may have similar results. For example, the postmodern movement has championed an irreverent and eclectic aesthetic spirit which challenges the very existence of a permanent canon. The postmodern spirit also assumes an integration of political, social, artistic, and literary life so fundamental as to challenge both disciplinary boundaries and the very theoretical and methodological approaches the traditional disciplines have taken to their subject matters.

\section{SOME EASILY OVERLOOKED AREAS}

In the following sections we have attempted to list a number of nondisciplinary and interdisciplinary literatures which seem to be especially vulnerable to oversight by selectors. Some of these are areas of ephemeral current interest, but most pose more permanent challenges. Insofar as possible, we have categorized these literatures according to the causes which make them so easily overlooked. Such an exercise in classification may serve to extend and refine the previous discussion of the reasons which account for the existence of collection development gaps. We also hope that the examples can serve as a very partial checklist for selectors' discussions about their respective areas of coverage.

\section{Nondisciplinary Areas}

1. Materials serving the public library function. Materials, including self-help materials, in problem areas such as alcoholism, drug or tobacco dependency, and the handicapped serve the legitimate and often important needs of individuals throughout the campus community, as well as external borrowers. Travel guides such as the Fodor's and Michelin's series are useful to university staff and students anticipating professional or personal travel, while materials on English as a second language are much needed by foreign students and their families. Also valuable to a large constituency are materials on finan- cial planning, tax preparation and avoidance, estates and probate, small business and the process of incorporation, home gardening, food preservation, sewing, carpentry, and other crafts or hobbies.

2. Materials serving nondepartmental campus agencies. A variety of administrative and quasi-administrative agencies on campus will typically have use of library materials, even though their literatures may fall outside disciplinary boundaries. Examples include the areas of fundraising and development; health and safety; career planning and placement; student activities; and equal opportunity and affirmative action.

3. Lay approaches to subjects within disciplinary boundaries. Whether a book falls within an academic discipline depends as much on the author's approach as on the subject matter. There is therefore a large body of literature which treats topics of interest to academic disciplines but is not disciplinary because of its theoretical approach or because of the kinds of data it considers to be valid.

A variety of naturalists have achieved literary distinction and provided highly stimulating insights into natural phenomenon without necessarily contributing to scientific progress. Lewis Thomas, Annie Dillard, and Stephen Jay Gould in his more popular writing exemplify this tradition. Popular books on how science is done, such as Ed Regis's Who Got Einstein's Office: Eccentricity and Genius at the Institute for Advanced Study also fall into this category, as do nonacademic surveys such as T.R. McDonough's The Search for Extraterrestial Intelligence: Listening for Life in the Cosmos, or David MacCaulay's splendid The Way Things Work.

Intelligent lay analyses of various societies provide a social science equivalent to the naturalist's essay. Frances Fitzgerald's Cities on a Hill is an example of popular sociology approaching literary status. Paul Theroux's Riding the Iron Rooster is only the most recent example of the literate travel book, a highly developed genre falling in this category.

The highly intelligent lay essay is a culturally important contribution, examples of which often attract academic attention 
in later years. In considering such materials, selectors should ask themselves whether their policies would support the acquisition of T.E. Lawrence's Seven Pillars of Wisdom or George Orwell's Homage to Catalonia, if these unquestioned masterpieces describing war and the politics of war were written today.

4. Cultural expressions not considered "Literature." Works in this grouping approach literary status but differ from the previous, related category because of the diffuseness of their subject matter. Thoughtful biographies such as James Reston's Growing Up or Annie Dillard's An American Childhood may be valuable additions to a collection. The reflective and socially revealing commentary of such humorists as P.J. O'Rourke, Dave Barry, Roy Blount, Jr., Calvin Trillin, and Woody Allen may be equally worthwhile contributions.

\section{Interdisciplinary Areas}

The acquisition of materials in interdisciplinary areas is even more critical to successful collection development than is the selection of a representative portion of the best nondisciplinary literatures. Here, after all, are materials whose topics and methodologies make them more or less academic in scope, even though they do not neatly match the interests of individual departments. The following examples illustrate the kinds of areas in which valuable interdisciplinary materials may easily be missed.

1. Materials with ambiguous classification numbers. As we have already indicated, books describing current political or social conditions in various parts of the world are generally classified in LC classes D through F. This practice does not necessarily reflect misclassification for the purposes of cataloging and retrieval, especially when the materials in question do not neatly reflect the perspectives of one or another individual social science. However, one result of such ambiguous classification practices may be to make selectors hesitate to acquire materials of potential value to area specialists in a variety of social science disciplines.

There are a number of other literatures whose typical call numbers may partially

\section{"There are a number of other litera- tures whose typical call numbers may partially misrepresent their subjects and may therefore tend to discourage selection or blur the division of re- sponsibilities."}

misrepresent their subjects and may therefore tend to discourage selection or blur the division of responsibilities. Many books in clinical psychology and psychotherapy classify in the R schedule. Although this classification accurately reflects the therapeutic orientation of these materials, it may tend to obscure the close relationship of such materials to mainstream psychology (BF). Indeed, data from Virginia Tech showed that faculty and graduate students in psychology relied fairly heavily on materials in class R. ${ }^{6}$

Books on gerontology classify in a number of areas, reflecting the disciplinary approaches of their authors but obscuring their common interests. Books on management as a science transcending particular applications in business administration are similarly scattered. Some are classified in sociology or psychology, although they may be of limited interest to selectors responsible for these disciplines. The emergence of Decision Science, with its close relationship to both cognitive psychology and artificial intelligence, has further diffused the scope of management materials.

2. Applied Areas. Areas of applied research tend to draw on the more fundamental understandings of a variety of disciplines, as the Manhattan Project drew on physics, engineering, and other areas. Normal collection development activities will not entirely overlook the literatures required for such work, but they may very well acquire substantially less material than is required for specific applied areas of interest on a given campus. A listing of specialized research centers at one's university, which often treat problems as specific as adhesion science, satellite communications, or synthetic fabrics, can be used to identify interdisciplinary areas of 
unusual interest to the campus community.

Issues of keen contemporary interest to the public as well as to professional researchers also show a marked tendency to occur at the boundaries and intersections of academic disciplines, rather than strictly within their boundaries. The following examples of current "hot topics" may be useful for illustrating this tendency. Because the examples listed are current issues, it is likely that an illustrative listing made five years from now would be entirely different.

Example 1: Materials on the economics of health care, including the HMO movement and the insurance crisis, span the boundaries of economics, medicine, and public policy.

Example 2: Recent materials on the crisis of third world debt treat an economic problem whose implications and possible solutions will be fundamentally political.

Example 3: Materials dealing with the regulation of business, whether in the context of consumer protection, antitrust, or the reduction of industrial pollution, are of potential interest to researchers in law, public policy, environmental studies, business, and other disciplines.

Example 4: Materials on AIDS raise a number of vexing economic, ethical, medical, and social questions, often bringing these domains together in new ways.

Example 5: Materials of strong interest to patrons in military science tend to scatter throughout a number of disciplines. It is not always clear to selectors whether topics such as arms reduction or the state of NATO belong to military or political science, or whether materials on SDI and other military technologies pertain more to military science or to engineering.

Example 6: Materials on Liberation Theology and Catholic radicalism assert a new relationship between religion and political life.

3. Miscellaneous areas inviting gaps. Several areas are especially seductive in raising selectors' beliefs that "Alphonse is buying that" for reasons that do not pertain to classification issues or the intersections of academic disciplines. Children's nonfiction is one such area: it would be perfectly plausible for the selector in children's literature to purchase only literature in the narrow sense (PZ), while selec- tors in other areas failed to acquire juvenile-level materials in history, biography, or science because they assumed that these areas were being covered. A similar and much more damaging instance could arise in the case of English translations of foreign literature. It would be all too easy for the works of both contemporary authors such as Garcia Marquez and canonized authors such as Proust to be ignored when published in translation because of the mutual deference of selectors in English and foreign languages.

\section{PREVENTING COLLECTION DEVELOPMENT GAPS}

Even though the persistence of collection development gaps is caused in part by such fundamental forces as the structure of collection development responsibilities or the winds of cultural change, many gaps can be prevented by collection development managers who are alert to the risks and practice relatively ordinary forms of vigilance. Naturally the academic library will wish to spend only a limited portion of its materials budget on materials of a nonacademic nature, however stimulating these may be. The necessity to limit such expenditures makes the principles of selection and the care with which they are applied even more critical.

Nondisciplinary areas of interest to the campus community can be identified. These are often ideal candidates for assignments to staff outside collection development who are seeking job enrichment. Generally these individuals will spend their limited collection development funds with enthusiasm and care. Collection development officers should include in their assignments academic disciplines not represented on their own campuses, as is often the case with such professional areas as medicine, journalism, and law.

The choice of appropriate selection tools is a key determinate of success in avoiding collection development gaps, as it is central to so many other aspects of success in selection efforts. In spending the relatively limited portion of its budget that will be accorded to explicitly nonacademic materials, the library's selectors will want 
to use tools that review books and do not merely provide imprint information. Our experience suggests that The New York Times Book Review - the source of most of the examples cited above-is an excellent vehicle for alerting selectors to recent publications that have high quality but do not use the theoretical perspectives of forms of data associated with traditional academic disciplines.

\section{"It is critical that the library foster an ethic that permits justified selection decisions outside of narrow discipli- nary boundaries."}

Collection development officers can also prevent the appearance of unnecessary gaps by encouraging communication among library selectors. All too often the issue of covering all areas of knowledge is discussed systematically only when approval plan profiles are revised. Physically centralized locations for the review of new materials can help to facilitate communi- cation among selectors. The routing of review journals and other selection tools will generally stimulate discussion, especially as selectors begin to see that their colleagues do not select in areas they had taken for granted.

In general, not taking anything for granted that has not been explicitly discussed is an excellent byword for the avoidance of gaps. One of the most important contributions a collection development manager can make is to lay out clear ground rules governing the selection of materials for which multiple selectors could be responsible. It is particularly important to determine which selector will normally be responsible when researchers from one department are known to be working in another discipline. Even beyond this, it is critical that the library foster an ethic that permits justified selection decisions outside of narrow disciplinary boundaries. It is far better that time be wasted beginning to process an order that turns out to be redundant than that selectors miss materials because they are territorial or have assumed that someone else is buying the next round.

\section{REFERENCES}

1. James A. Cogswell, "The Organization of Collection Management Functions in Academic Research Libraries," Journal of Academic Librarianship 13:268-76 (Nov. 1987).

2. Charles B. Osburn, Academic Research and Library Resources (Westport, Conn.: Greenwood, 1979).

3. Thomas S. Kuhn, The Structure of Scientific Revolutions 2d ed., enlarged. International Encyclopedia of Unified Science v.2, no.2 (Chicago: Univ. of Chicago, 1970).

4. Betsy Draine, "Academic Feminists Must Make Sure Their Commitments Are Not Self-Serving," The Chronicle of Higher Education Aug. 10, 1988, p.40.

5. Todd Gitlin, "Hip-Deep in Postmodernism," New York Times Book Review Nov. 6, 1988, p.1, 35-36.

6. Paul Metz, The Landscape of Literatures: Use of Subject Collections in a University Library (Chicago: American Library Assn., 1983), p.43, 127. 